\title{
A Probe into the Reform of Math Education under the Mode of Internationalized Talents Training in Engineering School
}

\author{
Chao Min, Yan Deng, Jingting Yang, Yanjie Hu \\ School of Science, Southwest Petroleum University, Chengdu, China \\ Email:minchao@swpu.edu.cn
}

How to cite this paper: Min, C., Deng, Y., Yang, J. T., \& Hu, Y. J. (2019). A Probe into the Reform of Math Education under the Mode of Internationalized Talents Training in Engineering School. Creative Education, 10, 962-971.

https://doi.org/10.4236/ce.2019.105072

Received: April 2, 2019

Accepted: May 18, 2019

Published: May 21, 2019

Copyright $\odot 2019$ by author(s) and Scientific Research Publishing Inc. This work is licensed under the Creative Commons Attribution International License (CC BY 4.0).

http://creativecommons.org/licenses/by/4.0/

\section{(c) (i) Open Access}

\begin{abstract}
Based on the guidance of the State and Sichuan Province's Medium and Long-term Education Reform and Development Plan (2010-2020), and the needs of economic construction in Sichuan Province and the western region, and on the basis of fully investigating of bilingual teaching models and methods at home and abroad, this paper studies the mathematics ability and foreign language level of the "international" talents needed by China's social economy. To meet this demand, some reform proposals are designed, such as the university mathematics curriculum system, bilingual curriculum teaching mode, after-school supervision and assessment methods, and the combination of discipline competition. This reform proposal lays the foundation for improving the quality of undergraduate teaching and cultivating innovative talents who can be integrated with the international community.
\end{abstract}

\section{Keywords}

International Talents Cultivation, Mathematics Curriculum System, Bilingual Teaching Mode, Reform in Education

\section{Introduction}

The Outline of the National Medium and Long-Term Education Reform and Development Plan puts forward to cultivate application-oriented talents, inter-disciplinary talents and top innovative talents which satisfy the needs of China's socioeconomic development; internationalization is an important embodiment among them. The so-called internationalized talents, we think they are such compound talents who are not only skilled at using foreign languages (English) for professional knowledge learning and communication, but also can independently focus on and master the most advanced international academic 
progress (Xinhua News Agency, 2010).

At present, the cultivation of internationalized talents is mainly embodied in the cooperation with oversea universities, to achieve joint training and expand international level. However, this model is relatively too expensive to suit for large-scale development in China. Promoting bilingual teaching is a good way to learn advanced foreign teaching concepts, teaching methods and educational methods. It can effectively improve students' professional English ability under the limited conditions, and cultivate international talents with comprehensive development in practice (Li \& Ding, 2016) (Wang, 2014).

However, from the current research situation, most bilingual courses are relatively "isolated" and it is difficult to have a continuous effect and influence on students. This isolation consists of two levels: one is the isolation of the bilingual curriculum system, which lacks both previously preparations and the follow-up development. It makes students difficult to learn at the beginning and forget to clean up the knowledge after the exam, which cannot achieve the purpose of truly cultivating international talents. Secondly, because the isolation between bilingual courses, and many professional bilingual courses have little connection with each other, students cannot form a systematic English "professional" thinking ability.

According to this, based on the mathematics teaching and bilingual curriculum construction of the undergraduate university, this paper investigates the problems existing in bilingual teaching and analyzes the university mathematics bilingual curriculum system and supporting reform plans about teaching, assessment and expansion mode, which adapt to the internationalized talents training. It also analyzes the English ability and professional knowledge that international students should possess, and further puts forward some suggestions, to realize the cultivation of internationalized talents step by step.

\section{The Results and Analysis of Questionnaire}

This paper investigates the bilingual teaching of the students majored in engineering of 4 grades through the form of an electric questionnaire, to learn about students' learning condition, build a more reasonable bilingual teaching mode between teachers and students, and improve bilingual teaching quality constantly. Totally 102 effective questionnaires are recovered, and the survey contents are mainly contained three parts.

First, the basic situation of students and their mastery of English. Understand students' mastery of English is important and essential for teachers to carry out bilingual teaching, by asking the grade about students, adoption of CET-4 and CET-6, and their understanding degree of the course in class, the survey results are shown in Table 1 and Table 2.

Through the investigation, we know that survey objects are mainly concentrated on junior (about 56.9\%) and senior (about 26.5\%), the rest $16.7 \%$ are freshman and sophomore. 63 students passed CET-4 (about 61.8\%) and 17 passed CET-6 (about 16.7\%), 10 students (about 9.8\%) are obtained the requirements 
Table 1. English Level for students.

\begin{tabular}{cccc}
\hline & CET4 & CET6 & Others \\
\hline Number & 63 & 17 & 22 \\
Percentage & 61.8 & 16.7 & 21.6 \\
\hline
\end{tabular}

Table 2. The understanding Level of Bilingualism for the students.

\begin{tabular}{cccc}
\hline & Full understand & Combined with Chinese materials & Can't understand \\
\hline Number & 8 & 81 & 13 \\
Percentage & 7.8 & 79.4 & 12.8 \\
\hline
\end{tabular}

of school for English and the rest (about 11.8\%) are other circumstances. In the survey respondent, there are $83.3 \%$ of students who ever taking the bilingual course, most of them are seniors. Only $7.8 \%$ students can fully understand the English teaching and $12.8 \%$ students cannot understand at all, the rest $79.4 \%$ can understand the bilingual course combined with the Chinese teaching material. The data displays that most students have a good command of English, which is good for the development of bilingual teaching, but from the actual situation, in terms of the level of understanding of the English course, students can't make good use of their English skill.

Second, the students' attitude to bilingual teaching. There are several questions, such as if necessary to taking bilingual course in universities, which grade is suited to take the course, is bilingual course helpful for studying abroad and reading foreign literature (Table 3 and Table 4).

With the results, there are more than 70 students (about $70.6 \%$ ) think it's benefit to have the bilingual course, and it's better in grade one or two. It means that students' attitude for bilingual teaching is positive and optimistic. Besides, there are 86 students (about $84.3 \%$ ) agree that bilingual course is helpful for them to study abroad, not only improve their ability to study professional knowledge, but also can broaden their international horizons, learn the advanced foreign education ideals.

Finally, the present situation of bilingual teaching. Under the existing teacher strength and teaching conditions, students are investigated to answer questions which course is suitable for bilingual, the teaching methods references. According to the results, $25.5 \%$ students are choosing a professional course to bilingualism, $24.5 \%$ students prefer public basic courses, only $9.8 \%$ choose a professional basic course, this shows that most students realize great importance to specialized courses (Table 5).

More than 40 students (about $42.2 \%$ ) think the English proportion should account for $30 \%$, and $31.4 \%$ students think about $50 \%-80 \%$. In addition, most students think the final exam should be given in a foreign language and answered freely, and 30\% think they should answer in Chinese. Which means that students' dependence on their mother tongue is very high, and lack the confidence of the ability to use English and the understanding that bilingual teaching must be carried out in English as the medium of language (Table 6). 
Table 3. The necessity of taking bilingual course.

\begin{tabular}{rcc}
\hline & Have necessary & Haven't necessary \\
\hline Number & 72 & 30 \\
Percentage & 70.6 & 29.4 \\
\hline
\end{tabular}

Table 4. Grades for bilingual courses.

\begin{tabular}{cccc}
\hline & Freshman & Sophomore & Junior and Senior \\
\hline Number & 41 & 48 & 13 \\
Percentage & 40.2 & 41.7 & 12.7 \\
\hline
\end{tabular}

Table 5. Proportion of bilingual teaching courses.

\begin{tabular}{ccccc}
\hline & Public Course & Professional basic course & Professional course & Both OK \\
\hline Number & 25 & 10 & 26 & 41 \\
Percentage & 24.5 & 9.8 & 25.5 & 40 \\
\hline
\end{tabular}

Table 6. Students' view about the proportion of English teaching.

\begin{tabular}{ccccc}
\hline & $30 \%$ & $50 \%-80 \%$ & $100 \%$ & No uniform standard \\
\hline Number & 43 & 32 & 3 & 24 \\
Percentage & 42.2 & 31.4 & 2.9 & 23.5 \\
\hline
\end{tabular}

All in all, according to the results of investigation, it's clear that students' attitude about carrying out bilingual course in our school is positive and supported. But there are some difficulties in many aspects, students cannot use English skillfully owing to lack of practicing in a long time, unfamiliar with professional words, even afriading of English teaching. All of these make bilingual teaching become difficult to set up in university, and cannot achieve the purpose of cultivating international talents. According to the specific situation of students and the teaching conditions of the school, this paper aims to put forward a scheme for the cultivation of international talents suitable for mathematics majors, mainly from the following aspects.

\section{Improvement of the Mathematics Curriculum System}

In order to form a complete professional knowledge and professional English system for students, and build a reasonable international class curriculum system, this paper systematically studies the level of professional English ability required by internationalized innovative talents based on the existing professional supporting settings, and combined with the results of questionnaire. It's necessary to clarify the requirements for professional English proficiency.

\subsection{Professional English Proficiency Requirements}

Starting from the indispensable ability of international talents, to combine the cognitive laws that students learn and accept knowledge, we believe that the cul- 
tivation of internationalized talents under the professional English ability should be divided into three levels:

1) The ability of General English

The general English here is not simply referring to the English ability which students mastered in college course, but should know and master further the English expression of the common sense about general science and technology. This is the first ability level that international talents should have. This should be cultivated consciously in the study of the basic course at the first year of university.

2) The ability of Basic Professional English

When students enter the sophomore and junior stages, and gradually begin to study the professional courses of their major, they need not only to master skillfully the frequently-used professional English vocabulary of their major, but also can read and study easily the professional foreign books to master professional knowledge. This is the main purpose of the current bilingual curriculum.

3) The ability of thinking with Professional English

At this level, students should form a system of professional English knowledge in their minds, be able to read professional English scientific literature freely, use professional English to think about problems, and write English articles. This level can only be achieved at the stage of postgraduate and doctoral students. But at the undergraduate level, we can achieve the preliminary preparation and link-up through innovative course research, discipline competition and so on.

\subsection{Improvement of the Existing Mathematics Curriculum System}

Internationalized talents cultivation cannot accomplish at one stroke, cannot achieve the purpose by one or two bilingual courses yet. English as a language, need practice and strengthen constantly. If the course ignores the coherence, it cannot attain the purpose of cultivating students. So, wholeness and coherence are the heart of cultivating professional English ability. Combined with the three level about professional English ability and the existing bilingual teaching mode, we have a detailed analysis and put forward suggestions of improvement.

1) Mathematics Curriculum System in University

At present, our school's internationalized talents cultivation is mainly focusing on international classes, according to the experience of teaching the international class course Probability Statistics (I), it's finding that the international class students' mathematics foundations, receptivity and comprehension are better than average level. But there are still existing some problems within teaching effect in class and teacher-student interaction, one is the lower initiative of international class students studying university mathematics course actively, another is present university mathematics course are easy for them, the lacking of depth and breadth are part reason. According to the situation, there are some suggestions for international class university mathematics course besides the normal stratified teaching:

Firstly, in the teaching content of university mathematics course, the English 
vocabulary, definition and basic theorem expression of frequently-used mathematics knowledge should clearly be the teaching content. It's benefit for students to possess general English ability before setting up bilingual course content.

Secondly, based on the existing syllabus, aimed at students' professional background and follow-up curriculum requirements, international class' university mathematics course should add some difficulty appropriately. For example, in the course of Advanced Mathematics, the students of international resource survey class should deepen the Fourier series and Fourier transform, also should expand appropriately to Laplace transform, all these contents are foundation of complex function and integral transformation; while for the international class students of petroleum engineering, it should emphasize Green formula and Gauss formula to ready for follow-up course of Equations in Math Physics.

Finally, the university mathematics courses are supposed to add task-based teaching content. Since international class are adopting small-class mostly, the number of students is small and the ability is strong. So from the course advanced algebra on, colleges may arrange appropriately some reality problem and task which can be solved by books' methods, it makes students study actively, think about problem seriously and cultivate the ability of study automatically.

2) Bilingual Curriculum System

As mentioned earlier, bilingual course is set to cultivate students' professional basic English ability which is the second level ability for students. Different professional bilingual course has different set certainly, but the core principle is connected with each other: concentrating on the integrity and relevance. Because of the professional restrictions, this paper only analyses and discusses the courses Operational Research and Numerical Analysis, which are the professional bilingual courses of mathematics and applied mathematics in the College of Science.

These two courses are involving basic knowledge in analysis, algebra, geometry, and even equations and so on. But both two courses have less connection with each other, and the professional English knowledge which involved are lacking of intersection, which can be solved by the advanced general English cultivation to lay the foundation.

By analyzing the necessary intermediate links between these two courses, we suggest that Mathematics Model and Mathematics Experiment should be set as bilingual course. Apart from the basis of fundamental mathematics knowledge, it is not only use Operations Research knowledge, but also Numerical Analysis methods. Therefore, it can be a belt to link those two courses, it's benefit for students to form an overall applied mathematics thinking, and master a systematical mathematics expertise.

3) The System of Contests vary in Disciplines

The third level of professional English ability cultivation is the hardest. But, we can consider adding discipline competition contents to achieve the preliminary cultivation of English thinking ability.

In the cases of limited teachers and human resources, discipline competition 
is a pretty good mean from mathematics competitions, mathematical modeling competitions to challenge cups, programming competitions, etc. Through mathematics-related competition and self-professional competition, students can cultivate competition awareness, team awareness, win a prize and further strengthen the learning enthusiasm.

In the process of participating these competitions, students can cultivate the ability of understanding and analyzing problem with an English thinking gradually by reading English literature and writing English essay. What' more, it can lay a solid foundation for the further development of the third level of ability in the postgraduate stage.

The three aspects of the system described above, continuous in time and gradual in knowledge and ability cultivation. Only to concentrate on wholeness and coherence consciously, it can really achieve the purpose of internationalized talents cultivation.

\section{Discussion of Bilingual Course Teaching System}

\subsection{Bilingual Curriculum Teaching Model}

We insist on the principle of theory combined with practice (Wu, 2007) ( $\mathrm{Li}$, 2005) (Teng, 2005) (Cheng, 2005), by using research methods of studying, piloting and summarizing to do a deep analysis about the existing problem in bilingual university mathematics courses teaching, and then, to do a reasonable bilingual teaching mode.

In the teaching of bilingual courses, we basically use a combination of multiple teaching mode to teach. However, on the basis of this, bilingual courses should do a further step adjustment appropriately due to its special features on teaching. Combined with my teaching experience and compared the teaching effect between basic courses and the further advanced course, it's believed that "step by step, persevere" is the core to the bilingual course teaching.

The bilingual courses are using the mode of English textbooks, English courseware and Chinese teaching, but in the course of teaching, students reflected that they do not understand universally. The reasons are mainly two aspects: in one hand, students never contact the English textbooks and English teaching mode before, if according to the normal schedule to begin English teaching, they are hard to adapt; in another hand, students are having a slow reading progress of English textbooks relatively, therefore, preview before class generally cannot catch up with the normal teaching progress. In view of this situation, in addition to recommending the corresponding Chinese reference books, we will also slow down the progress of the lectures at the beginning of the course to give students a process of adaptation.

\subsection{The Reasonable Bilingual Courses Supervision After-School and Assessments Methods}

As the example of Operations Research bilingual course and Data Analysis bilingual course, the mode we present use to assess is the usual grades $(20 \%)+$ big 
assignment (20\%) + final exam (60\%). Among them, the usual grades mainly include attendance, homework; the big assignments mainly refer to some practical application cases and problems, which needs to be programmed to achieve. According to the assessment results and student feedback, there are still existing some problem:

Firstly, because these two are professional courses, students do not only need the basis of understanding the English textbooks and courseware, but also understand further professional knowledge. So classroom answering and after-school homework are not at good effective. We need to solve this problem fundamentally, through the gradual progress and continuous reinforcement of bilingual courses from the lower grades to the upper grades, students are gradually accustomed to this class mode, and then catch up with the progress of the class and complete the class work.

Secondly, in view of present task-based teaching mode, the best effective homework assessment method is group placement project, organize regular discussion and guidance, and finally complete the project report, which is an effective means of implementation of case teaching. It's also a general practice of professional courses in foreign countries.

Above all, based on the present big assignment assessment, with the goal of adding teachers' average guidance time to students' per unit of time, there are some suggestions as follow:

1) Based on the present teaching hours, shorted the bilingual courses' learning quantity per week and extended the courses cycle, which will give students sufficient time to digest and absorb knowledge, and finish the classwork, in this way, students can think about the question which listed in big assignment, and teachers may have enough time to guide separately.

2) Give fully play to postgraduate (even senior high students in undergraduate) assistants, students are divided into a group with three to five person with the whole guidance by teachers and specific task by assistants. This will relief teacher from complicated things, and concentrate on promoting teaching quality, on the contrary, students can get more guidance from assistants even increase learning effect.

3) Suggesting that mathematics teachers strengthen the cooperation with students' other professional teachers in this semester to set up big assignments. In one thing, it can enable teachers to work together and reduce the amount of guidance; in another thing, it can help students apply the mathematics knowledge to their professional issues, recognize how the mathematics is used, and cultivate their learning interest.

\subsection{The Thinking of Further Enhancing Students' Ability Based on the Mathematics Model Competition}

In the basis on using bilingual courses teaching system to cultivate students' ability of mathematics knowledge and mathematics English expression and communication, we further encourage the students to join in the Mathematical 
Contest in Modeling(MCM), which will improve their ability of English reading and English essay writing.

The Mathematical Contest in Modeling (MCM) is a comprehensive test for students' mathematics and English level (Zhao, 2008) (Quan, 2016). Because the more open and more interesting of the competition topic, at the same time, winning a prize is of vital importance for students to study abroad, and many students frequently are absorbed in it. Therefore, we are spare no efforts to make the competition as a supplement for course teaching, cultivate students' encouragement by joining competition, improve their ability of English reading and English essay writing. Students can achieve full English read and write, so that they can finish the "flip courses" teaching under the progress with students' discussion and teachers' instruction.

\section{Conclusion}

In totally, this paper is mainly to research the wholeness and connection between courses; by cultivating gradually, students can possess systematically and integrally professional English knowledge. First, when setting up bilingual courses, we should adhere to the way of combining Chinese and English, and consider teaching in different classes, and gradually increase the proportion of English teaching. Secondly, it is necessary to make it clear that the main body of bilingual teaching is students, while the role of teachers is auxiliary teaching and paying attention to communication with students in class and partition panel discussion, which can improve their learning interest, self-confident and innovation. Thirdly, the English textbooks used by students should be accompanied by appropriate Chinese reference books. For some remote professional vocabulary, teachers should do a good job of statistics and Chinese-English comparison in advance, so as to facilitate students' understanding. Finally, on the basis of bilingual teaching of the existing specialized courses, the proportion of bilingual courses of public basic courses and elective courses should be appropriately added to meet the needs of students with different English levels. In addition, the examination of bilingual courses can increase the proportion of ordinary results; the application of "bonus system" to the students participating in classroom activities and recording in the final results can not only reduce students' fear of difficulties in bilingual courses, but also encourage students to participate in bilingual classroom enthusiasm. Combined with mathematics basic courses, bilingual courses and after-class subject contests, students of different levels can methodically strengthen during the progress, and then master relatively professional English, and even understand advanced research domestic and foreign. This project has consciously been preliminary practiced in the author' daily teaching task. In future research, we will continue to deepen and improve this project, deepen the connection between university mathematics courses and student professional background needs, gradually form an overall supporting training program, and then achieve the purpose of internationalized talents. 


\section{Support}

This work is supported by the project of cooperative student cultivation by schools and cooperation from the ministry of education in China (201801209016).

\section{Conflicts of Interest}

The authors declare no conflicts of interest regarding the publication of this paper.

\section{References}

Cheng, X. Y. (2005). A Preliminary Study of Bilingual Teaching Models in Chinese Universities. Journal of Xi'an International Studies University, 13, 89-91.

Li, H. J., \& Ding, D. (2016). Exploration and Research on the Cultivation of Top Talents in Science from Perspective of Internationalization-Taking Hua Luogeng Experimental Class in Beijing University of Aeronautics and Astronautics as an Example. Journal of Beijing University of Aeronautics and Astronautics (Social Science Edition), 29, 112-116.

Li, H. X. (2005). The Status and Trend of Bilingual Teaching in Colleges and Universities. China Geological Education, 14, 118-121.

Quan, Y. M. (2016). The Cultivation of Creativity of Engineering Students in the International Atmosphere. Research on Higher Engineering Education, 5, 85-89.

Teng, X. Y. (2005). Exploration and Experience of Bilingual Teaching. Chinese University Teaching, No. 7, 31-32.

Wang, X. H. (2014). Research on Personalized Personnel Training Model of First-Class. Ph.D. Thesis, Wuhan: Central China Normal University.

Wu, P. (2007). A Review of Bilingual Teaching Research in the Past Five Years Chinese University Teaching. No. 1, 39-47.

Xinhua News Agency (2010). Outline of the national Medium and Long-Term Education Reform and Development Plan (2010-2020). http://www.gov.cn/jrzg/2010-07/29/content_1667143.htm

Zhao, S. F. (2008). The Connotation and Cultural Characteristics of the Quality Training of Mathematical Modeling Education. Ph.D. Thesis, Changchun: Jilin University. 